Artículo. Verónica Sentis Herrmann y Braulio Rojas Castro. "Huachos, rotos y putas. La dramaturgia de Valparaíso frente a la cuestión social".

\title{
HUACHOS, ROTOS Y PUTAS. LA DRAMATURGIA DE VALPARAÍSO FRENTE A LA CUESTIÓN SOCIAL
}

\section{HUACHOS, ROTOS AND PUTAS. THE DRAMA OF VALPARAISO IN THE FACE OF THE SOCIAL MATTER}

\author{
Dra. Verónica Sentis Herrmann \\ Universidad de Playa Ancha \\ vsentis@upla.cl \\ Dr. Braulio Rojas Castro \\ Universidad de Playa Ancha \\ braulio.rojas@upla.cl
}

\begin{abstract}
RESUMEN
El presente artículo analiza de qué manera la dramaturgia sobre Valparaíso, producida entre 1891 y 1936, se hizo eco de la cuestión social proponiendo desde el universo poético las figuras de "el huacho" como origen de la inequidad de clases, "el roto", como la evolución del huacho, y "la puta" como madre del primero y posible mujer del segundo. Estéticamente, se plantea que si bien la concomitancia temática de las producciones teatrales del período es coincidente con la tematización que se hizo desde la literatura en relación a los personajes antes aludidos, la narrativa porteña comenzó a evidenciar una evolución formal hacia las vanguardias incorporando nuevos estilos, mientras el teatro continuaba anclado en una concepción naturalista-melodramática. Se postula que lo anterior tendría su explicación en las diferencias de circulación de ambos objetos estéticos, dado que la literatura puede trascender el tiempo mediando su relación y el gusto de los lectores en su condición de texto editado. Sin embargo, la puesta en escena en tanto acontecimiento, resulta limitada por las preferencias de los posibles espectadores, quienes determinan su supervivencia económica a través de la concurrencia a los espectáculos, retrasando los procedimientos experimentales vanguardistas.
\end{abstract}

Palabras claves: Dramaturgia, teatro de Valparaíso, cuestión social, melodrama, vanguardismo.

\section{ABSTRACT}

This article analyses how drama about Valparaiso, produced between 1891 and 1938, echoed the social matter by proposing, from a poetic perspective, 'huacho' as a class inequality concept, 'roto' as the evolution of 'huacho', and 'puta' as the mother of the first and possible wife of the latter. It is suggested, from an aesthetic point of view, that while there is coincidence between the theatre productions and the literture of the period in relation to said characters, Valparaiso literary narrative began to show a formal evolution towards the avant-garde, incorporating new styles, while theatre continued to be anchored in a naturalistic-melodramatic conception. It is proposed that this difference can be explained by the way both aesthetic objects circulated, given that literature can 
Nueva Revista del Pacífico 2020, № 72, (pp. 301-324). ISSN (e) 0719-5176

transcend time by mediating its relationship with the taste of the readers as an edited text, but the staging, as an event, is limited by the preferences of the potential spectators who determine its economic survival by attending the shows, delaying avant-garde experimental procedures.

Keywords: Dramaturgy, Valparaíso theater, social matter, melodrama, avant-garde

Recibido: 08 de junio de 2020

Aceptado: 22 de junio de 2020

\section{Introducción: acercamiento al contexto de producción}

La principal reacción que tuvo la Iglesia Católica frente al ascenso y difusión de los movimientos filo socialistas europeos de la segunda mitad del siglo XIX, fue la publicación de la encíclica papal De rerum novarum en 1891. En ella, el papa León XIII pretendía explicitar la perspectiva de la iglesia frente a los cambios sociales generados por la industrialización, persuadir a los empresarios de compartir en mayor grado sus ganancias económicas con la clase trabajadora y alertar a los gobernantes sobre "las muy difíciles condiciones de vida y laborales en las que se encontraban grandes masas de obreros, campesinos y habitantes de los suburbios de las grandes ciudades" (Hurtado, Teatro 147). Además, intentaba detener el descrédito en que había caído la institución eclesiástica al identificarse exclusivamente con los intereses de las oligarquías, reconociendo el derecho a sindicalización de los asalariados. Sin embargo, la encíclica no cuestionaba el valor de la propiedad privada y del trabajo capitalista. Por el contrario, predicaba una mirada más distributiva como estrategia para prevenir radicalizaciones políticas generadoras de movimientos disruptivos, tales como el anarquismo europeo del siglo XIX, instando a los pobres a rezar por un trato mejor y por el desarrollo de la paciencia, a semejanza de Jesús (León XIII, párrafo 19, en línea).

En Chile, así como en el resto de la región, la relación de subordinación de las clases más desposeídas se había mantenido conflictivamente dentro del nuevo orden republicano, a pesar de que constituían la verdadera fuerza de trabajo para lograr la ansiada modernización capitalista (Lepe- Carrión 19-20). La oligarquía chilena no se hacía eco de las malas condiciones de vida de las clases populares, lo que implicaba un peligro tanto para la estabilidad como para la legitimidad del Estado (Salazar y Pinto, Estado, 
Artículo. Verónica Sentis Herrmann y Braulio Rojas Castro. "Huachos, rotos y putas. La dramaturgia de Valparaíso frente a la cuestión social".

legitimidad y ciudadanía). Lo anterior determinó la aparición del tema de la "cuestión social" en la literatura y el teatro chileno, manifestaciones que comenzaron a expresar la crisis de los valores de la ilustración. Para ello, se expusieron las desigualdades de los procesos de modernización y el surgimiento de sectores marginalizados de la sociedad y, través de textos literarios y dramáticos, se abordó la injusticia del sistema (Villegas 137138).

En términos literarios, este período estuvo marcado por el movimiento paulatino del costumbrismo al criollismo entre los años 1890 al 1900 (Muñoz y Oelker 88 y ss.), entendido este último como una escritura que tiene "como valor predominante la observación documentada del medio nacional" (Durán-Cerda 299). Lo anterior se proponía en pugna con el modernismo -situado entre los años 1888 con la publicación de Azul y 1916 con la muerte de Darío (Muñoz y Oelker 64)- ${ }^{1}$, concibiendose en términos como lo documenta Subercaseaux, a saber, como "una opción contrahegemónica a los correlatos sociales y culturales de la modernización (positivismo, centificismo, empirismo, laicismo)" (Ctd. en Muñoz y Oelker 63) ${ }^{2}$. En el punto de cierre del corte cronológico, es relevante destacar la forma como se han teorizado los movimientos de vanguardia, considerando que: "hechos históricos, sociales, económicos apremiantes, y apetencias artísiticas vinculadas a las rersonancias del vanguardismo, producidos en la década de 1930-1940, van a conmover profundamente el ámbito cultural del país y van a determinar una conformación literaria de fisonomía muy particular (Durán-Cerda 305306), pues, como lo señala Bosshard, en el paso del Modernismo al Vanguardismo, “estamos en una constelación en la cual, a pesar de que ni la modernización tecnológica (revolución industrial) ni la modernización social (aburguesamiento) han alcanzado la misma dinámica que en Europa, la producción estética americana está -por primera vez- al mismo nivel que la europea” (397). Se situará la discusión en la singularidad de la

\footnotetext{
${ }^{1}$ Otros autores, como Acereda (2011), sitúan el modernismo entre 1882, con la publicación de "varios escritos de José Martí [hasta la publicación de] Lo cálices vacíos (1913) de Delmira Agostini” (65-66). No nos pronunciaremos sobre este punto, por espacio y porque se escapa de nuestro tema, asumiendo como referencia lo anotado por Muñoz y Oelker.

${ }^{2}$ Acereda (2011) señala que: "el Modernismo propone la edificación de una poética de carácter moral y estético que busca sustituir los constituyentes claves del positivismo y del mero utilitarismo por los ideales del arte y del hombre como ser individual y responsable de sus propios actos y, en literatura, de su propia obra. [...] Es en esa dimensión crítica donde el Modernismo no encuentra un espacio público claro y donde sus artistas y poetas sufrirán una marginación que les llevará a la rebeldía y a la instauración de un arte y un lenguaje cuidadosamente elaborado en busca de reconocimiento" (74).
} 
vanguardia literaria de Valparaíso, y en el hecho de cómo este proceso es escasamente recepcionado en la dramaturgia porteña. ${ }^{3}$

Cabe señalar que, tanto la producción literaria como dramatúrgica del período, habla de las clases populares y subordinadas desde el lugar social que tienen los creadores. Dichos autores, en su gran mayoría inscritos en una burguesía ilustrada, incorporaron dentro del espectro argumental los conflictos de los desposeídos. En el caso particular de Valparaíso, punto de ingreso de la modernización capitalista a Chile, se plasmó la experiencia de aquellos que mal vivían en el puerto buscando en los bordes de la sociedad alternativas de subsistencia. Consecuentemente, tras los primeros treinta años del siglo XX, se configuró un corpus de obras literarias y dramáticas que bosquejaron personajes del mundo local. Seres que deambulaban entre los cerros y el mar buscando oportunidades para resolver la subsistencia, tejiendo un imaginario urbano particular y marginal sobre la ciudad-puerto y sus moradores.

En el ámbito del teatro ${ }^{4}$, el público destinatario de estas creaciones era la pequeña burguesía en ascenso, que había conseguido una mejora económica y acceso a la educación y, en ningún caso, los propios obreros o proletarios protagonistas de las piezas 5 (Villegas 147).

\section{Huachos, rotos y putas como imágenes de la exclusión y la miseria}

Desde fines del siglo XIX y durante las primeras décadas del siglo XX, dada la proporción objetiva de niños ilegítimos en $\mathrm{Chile}^{6}$, la literatura y la dramaturgia porteña se poblaron de huachos: "Huérfanos ilegítimos, producto de un cruce de linajes y estirpes a

\footnotetext{
${ }^{3}$ El corte cronológico propuesto dice relación con el período comprendido entre la emergencia de la cuestión social, asociada a la difusión de la encíclica Rerum novarum (1891), y el proceso que va, siguiendo a Salazar, "del movimiento cívico soberano del período 1890-1925 en el dependiente movimiento de masas" (Movimientos sociales 33 y ss.) de la década del 30, teniendo como punto de corte el surgimiento del Frente Popular en Chile el año 1936.

${ }^{4}$ Para este análisis, se concibe la literatura y la dramaturgia como textualidades diferenciadas, pues dadas las características del objeto estético "obra de teatro", entendemos que "cuando le[emos] un texto teatral no est[amos] ante literatura dramática, sino ante una puesta en escena y un público potencial" (Hurtado, Dramaturgia 15).

${ }^{5}$ Cabe destacar que las piezas citadas fueron montadas dentro del período abordado (1891-1938), sin embargo, varias de ellas han sido publicadas como tales recién el año 2019 (Sentis Herrmann Valparaíso; La ciudad). En consonancia, las obras aludidas cumplen con el requisito de haber sido estrenadas en su época, frente a un público en desarrollo.

${ }^{6}$ Entre 1848 y 1916 los niños ilegítimos nacidos en Chile alcanzaba el 38\% del total. En la ciudad de Santiago la cifra se acercaba al 50\% (Salazar, Ser Niño 78-79).
} 
Artículo. Verónica Sentis Herrmann y Braulio Rojas Castro. "Huachos, rotos y putas. La dramaturgia de Valparaíso frente a la cuestión social".

veces equívocos, a veces prístinos. Bastardía temida y por ello olvidada, ilegitimidad que conforma una manera de ver el mundo" (Montecinos 16). Se constituye así un "huacharaje", en virtud de "la relación psicosocial morbosa que se teje y desteje entre un padre ausente (en su origen el Conquistador español) y la madre (india) abandonada con su prole (mestiza), quien asume un rol compensatorio sobreprotector que termina por abortar la libertad misma de los hijos a quienes protege" (Hozven 328). El huacho fue considerado como un niño crecido en la desprotección, ya sea como resultado de una acción particular encarnada en un padre que no le otorga su apellido ni la manutención que se le debe a la infancia, o a consecuencia del abandono del Estado el que, más allá de los discursos oficiales, no se hace cargo de cautelar los derechos de los desfavorecidos (Salazar, Ser niño). En este contexto, el discurso ficcional se hace cargo de evidenciar a un sujeto que ha aparecido como no histórico, que carece de poder, y que más que construir la historia, la sufre, constituyéndose en el reflejo subjetivo de la implementación del modelo capitalista modernizador ${ }^{7}$. Estas obras son ilustraciones de la preocupación que empezaba a causar la pobreza como problema social, en especial la del "niño proletario chileno, creativo, sobreviviente de las miserias y determinaciones de las estructuras, sabedor de mil oficios, conocedor de mundos ajenos, crónico desertor de escuela, incisivo cateador de la mentalidad de los caballeros y de las debilidades caritativo-culturales de la sociedad ilustrada" (Illanes 13).

Posteriormente, este niño ilegítimo se transmuta en su adultez en la figura de "el roto", personaje que dada la imposibilidad de estudiar y acceder a los beneficios de las otras capas sociales, se mantiene en la marginalidad arrostrando en su vida adulta las consecuencias de no poder competir dentro del mercado laboral en igualdad de condiciones (Salazar, Ser niño 122). El roto es la alegoría del mestizo, huacho de origen, que se enarbola como elemento identitario de la nación (Lepe- Carrión 2016). Consecuentemente, y según la necesidad de los discursos oficiales, se denosta o alaba su mezcla de español e india o de patrón y empleada, metamorfoseado en trabajador esforzado que no desea -ni debe desear- abandonar su lugar en la pirámide de clases y constituiría lo que genéricamente se entiende como pueblo (Montecinos 125).

\footnotetext{
${ }^{7}$ Comentamos que estas narrativas están escritas desde la perspectiva de la picaresca española (Sullivan 293 y ss.) (Correa-Díaz 2008), si bien no hay espacio para ahondar en este aspecto.
} 
Junto a ellos aparece la figura femenina, frecuentemente descrita como prostituta, a la vez que madre o mujer de los anteriores. Es "definida por su carnalidad, por su eroticidad que la guía y sella su destino" (Montecinos 133). En su condición de madre soltera y mestiza, hembra abandonada y desprotegida por el sistema social, recurre a la venta de su cuerpo en el mercado como único bien transable ${ }^{8}$, cuya imagen está "ligada a la gran urbe moderna donde circula como mercancía" (Cánovas 19). En su relación con el huacho, es una madre sobredimensionada al convertirse en el único rol parental presente, que se mantiene junto a sus hijos frente a la desaparición del padre ${ }^{9}$. Por lo mismo, debe resolver en soledad la subsistencia de sus vástagos a través de variadas estrategias, según el ambiente en que se desenvuelve. Es lavandera, sirvienta, operaria y a veces chinganera o prostituta, como una alternativa más productiva para enfrentar la pobreza, opción perseguida por la ley y la iglesia, que acusándola de inmoral la envían de sirvienta "a mérito y sin salario" (Salazar Ser niño 42). Cuando ese es el caso, sus hijos son entregados a hogares de niños expósitos o como criados sin sueldo en las mansiones señoriales ${ }^{10}$. Como pareja, es una mujer que no responde a los valores morales cristianos. No es virgen. Vive amancebada. Tiene hijos de hombres anteriores y, muchas veces, mantiene un lacho, "varón [que] presta protección a la hembra, a cambio de vivir ocioso y mantenido por su protegida" (Montecinos 47), noción que aparece ligada a la prostitución de los enclaves mineros. En la realidad, frecuentemente solo decía relación con el estado de concubinato.

Estos tres personajes tipos: "el huacho", "el roto" y "la puta", se constituyen en imágenes estéticas que alegorizan el fracaso del proyecto unitario de nación, tramados

\footnotetext{
${ }^{8}$ En su estudio sobre hombría y feminidad, Salazar y Pinto señalan que dada la constante reducción del trabajo asalariado femenino en la primera década del siglo XX, para 1917 se podría decir que en la capital "una de cada cuatro mujeres adultas estaba involucrada en actividades de prostitución [y] probablemente, existían en el país tantas prostitutas como lavanderas" (Historia, 156)

${ }^{9}$ Es interesante considerar lo que plantea Salazar en Ser niño huacho en Chile respecto a la ausencia masculina, quien no propone una visión esencialista en la que el padre es naturalmente más desapegado de sus crías, sino que evidencia a través de una mirada contextuada los motivos de su alejamiento. Cuando es un peón, vale decir un trabajador "a ración y sin salario" (Ser niño 23) debe mantener una vida nómada en busca de la subsistencia. Como inquilino, parcelero u obrero, reproduce la relación de subordinación y explotación a la cual él mismo está expuesto. Cuando es un señor, su derecho se extiende hasta las mujeres de las clases populares, pues la familia de sus sirvientes "también es tratada como propiedad de ellos" (Ser niño 25). Además, en estos casos, tener un hijo del patrón era considerado un ascenso dentro de la escala social, a pesar de mantener su ilegitimidad.

10 “¡Pobre mamá! Su callejón, sin salida, era de ida y vuelta: de sirviente a puta y de puta a sirviente. Y en ese callejón crecíamos nosotros. Era nuestro modo de ser huachos.” (Salazar Ser niño 42)
} 
indisolublemente en los universos poéticos que abordan la vida del puerto (Chandía 2013). A través de los lugares de acción se propone un imaginario urbano que enmarca los sucesos, donde las características de la ciudad generan una particularidad geocultural, colectiva y diferencial (Nordenflycht La vanguardia 164), determinada por el modo en que habitan dicho paisaje.

Desde la literatura que tiene como imaginario diferencial (Nordenflycht Quiñonez 2003) a Valparaíso, la imagen del huacho ha sido trabajado por Pezoa Véliz en sus crónicas, como "El niño diablo" (1905), "muchachón endemoniado si los hay, vigoroso de puños y ágil de palabra" (Pezoa Véliz 27). También lo ha hecho Armando Méndez Carrasco en la novela El Mundo herido (1955), que relata la vida de los niños pobres en los cerros marginales de Valparaíso. Por otra parte, la de la prostituta ha sido tratada desde una perspectiva naturalista e higienista, como la que se describe en La Ciudad podrida de Carlos del Mudo en 1937. ${ }^{11}$

Como lo ha señalado Rojas Castro, en las escrituras marginales, o menores, se establece una relación con el espacio imaginario de Valparaíso, que marca, de formas más o menos intensas las obras, pues "esta imagen de «lo porteño» era portadora de un índice de emancipación, que más allá de ser efectivo, o no, movilizaba las energías y las fuerzas de estos sectores sociales" (Rojas Castro 2010 en línea).

\section{Naturalismo, melodrama y vanguardia: distintas formas para un mismo contenido}

Como resultado de la transferencia del modelo cultural francés tras las independencias latinoamericanas, el mundo del arte en Chile sufrió "una acción o proceso complejo de influencias y trasvasije por parte del foco cultural referencial (Francia) y de receptividad, reproducción y/o de apropiación por parte del centro epigonal (Chile)" (Conejeros 17). Lo anterior derivó en el ingreso del naturalismo como corriente literaria hegemónica a fines del siglo XIX y durante el primer tercio del siglo XX. La producción porteña no fue una excepción, y tanto las letras como el arte dramático volvieron la mirada a los bajos fondos urbanos y a los conceptos de herencia y medio ambiente, narrando implícitamente las

\footnotetext{
${ }^{11}$ Para entender estas producciones no se puede dejar de mencionar El roto (1920), de Edwards Bello, texto que se constituye en una creación referencial para tratar el problema de la pobreza y la marginalidad en Chile.
} 
contradicciones del proceso de modernización desde una postura que aspiraba a ser imparcial y objetiva. En este contexto, se incorporaron dentro de "los roles protagónicos, a aquellos sectores humanos no considerados: el bajo pueblo o cuarto estado. Sirvientes, campesinos, mineros, empleadas domésticas, mendigos, borrachos, dependientes de comercio, hombres de condición miserable, empleados de segunda categoría," (Balat 146).

A pesar de que el naturalismo era considerado la forma canónica del momento en la narrativa, en pugna con los devaneos modernistas y las avanzadas vanguardistas, lo cierto es que en el caso del teatro el estilo más recurrido desde 1910 en adelante fue el melodrama social (Hurtado, Dramaturgia 114 ). Y, si bien este género intentaba describir detalladamente el ambiente de los bajos fondos urbanos en sincronía con la perspectiva naturalista, lo hacía a través de recursos que perseguían la identificación emocional mediante personajes maniqueos en su bondad o maldad, sometidos a coincidencias y a situaciones exageradas y límites. Así, a través del recurso melodramático se buscaba, por una parte, informarnos sobre la vida de los desposeídos de la patria y, por otra, conmovernos mediante la exacerbación de las pasiones, utilizando giros inesperados de la acción. De este modo, si bien lo melodramático contó con cierto descrédito dentro de las clases ilustradas, gozó de una enorme aceptación en las clases medias y populares al incorporar lo emocional como un elemento catártico dentro de la vida civilizada (Bentley 193).

Por otra parte, junto con la adopción del estilo, el teatro chileno de la época comenzó a mostrar una mayor claridad de su especificidad artística. Ya no era sólo otra estrategia discursiva usada con fines de propaganda y difusión política a través de la edición de sus textos -como había ocurrido con el teatro independentista y de inicios de la república- sino que consciente de su esencia convivial logró "un mayor nivel de diferenciación como lenguaje, propendiendo a conformar un campo especializado de elaboración simbólica” (Hurtado, Dramaturgia 37).

Consecuentemente, las compañías profesionales locales, que vivieron su nacimiento y auge entre 1910 y 1940, comprendieron que el "modo de atraer al público [era] mediante piezas chilenas que pintasen asuntos nacionales" (Piña 170). Dicho surgimiento propició y se combinó con la aparición de nuevos dramaturgos, los que encontraron en ellas la 
Artículo. Verónica Sentis Herrmann y Braulio Rojas Castro. "Huachos, rotos y putas. La dramaturgia de Valparaíso frente a la cuestión social".

posibilidad de ver sus obras estrenadas. La producción dramática del período fue prolífera y los autores se hicieron parte del debate sociocultural, a través de montajes que incorporaban las tensiones sociales del momento. Los nuevos temas mostraban la clara división de privilegios de clase de la sociedad chilena, los conflictos de la migración campo-ciudad en el proceso de modernización, la desprotección de las mujeres populares y sus hijos, desapareciendo las piezas que proponían un sentido de unidad nacional, producción preponderante durante las últimas décadas del siglo XIX.

Un elemento que nos interesa destacar en el análisis, es el desacople estético y formal que se produce entre la dramaturgia y la literatura al momento de la irrupción del vanguardismo en Chile, el que se configura a partir de los intentos de superación del Modernismo, "con el surgimiento de tendencias renovadoras muy dispersas en matices y alcances" (Muñoz y Oelker 153). Desde una perspectiva formal, el vanguardismo se define por una relación ambigua entre "lo humano y lo deshumanizado, entre escrituras antimiméticas y escrituras realistas” (Bosshard 7). Además, como lo señala Montero, “el cosmopolitismo vanguardista incorpora ciertos elementos de la urbe que el modernismo dejó de lado: las capas bajas, lo antiestético, la máquina, la muchedumbre” (Montero 40). Nos situamos en este análisis desde una posición descentrada de las vanguardias literarias en Chile, las que "han sido conceptualizadas desde categorías construidas en la metrópoli, tendiendo a invisibilizar las diferencias y singularidades de los procesos paralelos en las provincias" (Rojas Castro Remenyik y Agrella 345). Para el caso de las vanguardias en Valparaíso, según como lo han constatado diferentes autores, esta tuvo la singularidad de ser de carácter expresionista (Nordenflycht 2011) (Alberdi 2013), siendo el grupo Rosa Náutica (1920-1921) el que expresa de manera más intensa este pathos: "La literatura creada en esos años, particularmente por Zsigmond Remenyik y Julio Walton, reflejó un giro hacia un conocimiento pleno del cotidiano de Valparaíso, sin discursos moralizantes, donde autores y personajes se funden en una misma experiencia y lenguaje” (Muñoz 187). Contrariamente, en el ámbito dramático, el primer caso de vanguardia teatral apareció de manera tardía respecto a la literatura. Fue Vicente Huidobro, considerado el poeta chileno vanguardista por antonomasia, el responsable de este aporte. Con su texto En la luna, retomó la tradición decimonónica de la farsa en una pieza de trazos satíricos que proponía como lugar de acción el satélite de la tierra. Si bien el tema de la obra estaba en 
consonancia con otras piezas de la época (desigualdad social, abuso de poder, indolencia respecto a las demandas de los más desposeídos, inconsciencia de las autoridades), su forma fue "rupturista, de vanguardia [y] anticipa el absurdo con elementos de Dadá. Por primera vez en el teatro chileno, hay una desarticulación del lenguaje y de la coherencia causa-efecto en la construcción sintáctica” (Hurtado, Teatro 173). Ahora bien, a pesar de haber sido escrita y editada en 1934 por la editorial Ercilla, no se llevó a escena sino hasta muchos años después, evidenciando con ello que el gusto del público no estaba preparado aún para este tipo de representación. Su estreno se realizó pasada la mitad del siglo, ${ }^{12}$ momento en que hizo su aparición el absurdo teatral, movimiento del cual la pieza de Huidobro puede considerarse precursora.

En el caso de Valparaíso, el vanguardismo y sus procedimientos formales tampoco tuvieron efecto en la producción teatral y dramatúrgica, quedando fijada esta entre el realismo, el naturalismo y el melodrama, sin avanzar hacia procesos experimentales y de ruptura en el campo.

\section{Mundo marginal y sus modos de representación en la producción teatral porteña}

Valparaíso, puerta de ingreso de la modernización nacional, fue retratado en las obras teatrales del período como un lugar de acción diferenciado con respecto a la metrópoli interior. ${ }^{13}$ Un puerto poblado de personajes populares que mal vivían en los recovecos y prostíbulos de la ciudad, asolados por la pobreza, la sífilis y el alcoholismo. Este grupo social mestizo, "los rotos", se constituyó en "la esencia cuantitativa y cualitativa de las 'clases bajas' emergentes [...] o 'plebe' chilena” (Lepe- Carrión 20), población que "se multiplicó de modo tan vertiginoso, que no pudo ser absorbida cultural y socialmente por ninguno de sus progenitores [indios o criollos españoles], convirtiéndose en cambio, por número, situación y proyección, en un gran tercer pueblo" (Salazar, Movimientos sociales 130-131).

\footnotetext{
${ }^{12}$ En Valparaíso fue estrenada recién en 1966, por la Compañía de Teatro del Instituto Pedagógico, bajo la dirección de Juan Barattini (Sentis, Historia 2012)

${ }^{13}$ La dramaturgia sobre Valparaíso -aquella cuyo lugar de acción poética es la ciudad puerto- es actualmente un campo en reconstrucción. En especial la producida durante la primera mitad del siglo XX. Dentro de ese corte se han logrado rescatar al día de hoy solo seis textos dramáticos, cuatro de los cuales aparecen aquí citados. En ese marco, el criterio de selección para incorporarlos en el presente artículo ha sido temático, en estrecha relación con los personajes estudiados.
} 
Artículo. Verónica Sentis Herrmann y Braulio Rojas Castro. "Huachos, rotos y putas. La dramaturgia de Valparaíso frente a la cuestión social".

Una de las primeras obras de "reivindicación de los sectores populares" (Hurtado, Dramaturgia 83), que expone los conflictos y el desprecio que sufren los desposeídos en la ciudad-puerto, es un texto anónimo, escrito para circo y estrenado en 1907, titulado Captura y fusilamiento de Dubois. Basado en el hecho histórico del juicio y ejecución del ciudadano francés Louis Amadeo Brihier Lacroix, profusamente cubierto por la prensa de la época, el autor denuncia la parcialidad del sistema judicial que representa los intereses de un Estado oligárquico. Entre sus aristas críticas rompe con la tradición dramática de fines del siglo XIX, que ensalzaba la imagen de "el roto" como estrategia identitaria forjada en el contexto de la guerra del Pacífico, y denuncia su subordinación dentro de la modernización capitalista. Por primera vez los personajes populares propuestos se alejan de los tipos risibles que utilizaba el juguete cómico en la dramaturgia precedente, para mostrarlos como seres humanos vulnerados en sus derechos por los propios representantes de la ley.

DUBOIS: ¿Y lo pillarán? [...]

AGENTE 1 $1^{\circ}$ : Espere un poco. (Va donde un roto que pasa y lo lleva a un lado). Date preso.

ROTO: ¿Y por qué pué? [...]

AGENTE: (A Dubois). Ve, ya tenemos al asesino. Ve como duda, el crimen lo acusa. No hay cuestión, es el autor de ese crimen. [...] (Al roto) ¿Qué hacías anoche en el pasaje Linford? ROTO: $[\ldots]$ ¿Anoche ondee i estado en el pasaje? No ve que estuve preso en la Primera porque mi pillaron curao. [...] No me voy a acordar yo, pues, cuando los pacos me pegaron tantazo porque no quería ir.

AGENTE $2^{\circ}$ : (Al primero). Compañero, ese roto miente, no cabe duda que es el criminal que buscamos. A la sección con él. Esta brillante captura nos valdrá un ascenso.

AGENTE 1: (Al tercero). Amárrale las manos. (Anónimo, citado en Sentis et al 12-13)

Otro aspecto aludido dentro de la pieza es el problema de los hijos huachos en la constitución del Chile moderno. La ilegitimidad de los vástagos, producto de una paternidad negada y amparada por el marco legal, se hace parte del conflicto de esta obra, temática recurrente en los autores de la primera mitad del siglo XX. Así, solo cuando el protagonista va a ser ejecutado accede a casarse con la mujer con quien se ha amancebado 
tenido un hijo, asegurándoles un mejor futuro tras su muerte. En ella, la resolución del conflicto parental dentro de la ficción poética se ejecuta en el ámbito del individuo. Si bien se critica tangencialmente la estructura legal del Estado, responsable de la injusticia que diferencia entre hijos naturales, legítimos e ilegítimos ${ }^{14}$, su superación depende de cada padre en particular. La limpieza de la honra femenina está sujeta al albedrío de la voluntad del hombre, no existiendo mecanismo legal que lo fuerce a asumir las responsabilidades que la paternidad implica. En ese sentido, el acto del personaje de Dubois lo enaltece moralmente, pues ha hecho algo a lo que no estaba obligado. No es un derecho del niño, ni el resultado de una sentencia, sino una concesión del padre hacia su hijo y la madre de éste, a la manera de una dádiva.
ABOGADO: ¿Por qué no se casa usted con Úrsula Morales? [...] por su hijo, ¿qué se pierde? [...]
DUBOIS: Acepto, sólo por usted y mi hijo [...]
ÚRSULA: (Entra silenciosa con el niño de la mano. Al ver a Dubois deja al niño y va a abrazarlo. Largo rato permanecen así) [...]
ABOGADO: (A Úrsula). He mandado a buscar el Oficial Civil porque Dubois consiente en casarse.
ÚRSULA: Gracias, señor, gracias. (18-19)

Por otra parte, si observamos la obra en relación a sus características formales, su estilo resalta como un elemento singular dentro del corpus. Si bien aborda los conflictos sociales transversales a la dramaturgia porteña de la época, no utiliza el recurso melodramático para sensibilizar al público. Es un drama que, en un intento de relato objetivo, expone situaciones $\mathrm{y}$ hechos que por sumatoria $\mathrm{y}$ sin recursos sobre emocionales, deja a las claras quiénes son los criminales.

Tal vez su particularidad formal se deba a que no fue concebida para una sala de teatro sino para el circo, manifestación escénica popular que en Latinoamérica presentó espectáculos de carácter intuitivamente naturalistas. En él "el público [...] se reconocía en el lenguaje, las actitudes y los actos de los personajes" (Versényi 113), debido, entre otros aspectos, a la proxemia cercana con la acción representada. La disposición circular del

\footnotetext{
${ }^{14}$ Recién en 1998 se aprobó en Chile una nueva Ley de Filiación (N¹9.585), la que reconoció igualdad de derechos a todos los niños nacidos en el país, más allá de la condición vincular de sus progenitores.
} 
Artículo. Verónica Sentis Herrmann y Braulio Rojas Castro. "Huachos, rotos y putas. La dramaturgia de Valparaíso frente a la cuestión social".

auditorio y la tendencia a utilizar elementos reales -entendidos como signos-objeto (Kowzan 1992) dentro del escenario de arena, permitía un ejercicio más realista y de menor convencionalidad interpretativa que el usado en los teatros configurados en herradura. Lamentablemente, el desconocer la identidad del autor no nos permite incorporar al análisis su origen de clase, lo que podría aportar luces respecto a su singularidad estilística, relacionando variables tales como estudios, formación e influencias.

Una segunda obra emplazada en la ciudad-puerto, cuyo conflicto aborda también el tema de los hijos huachos y las diferencias de clase dentro de la sociedad de la época, es El hijo de Nadie, de Julio Walton ${ }^{15}$. La trama gira expresamente en torno al reconocimiento de un hijo natural, resultado de la relación amorosa entre una joven modista de la clase trabajadora, "mujer pobre pero honrada" (Walton s/p) y un incipiente y joven pintor de la pequeña burguesía. A través de los parlamentos se exponen las posturas en disputa, las que varían según el origen social del hablante. De este modo, nos enteramos que los amigos del artista, estudiantes universitarios de la carrera de Derecho y futuros abogados, cuestionan teóricamente la disposición legal que permite a los padres no reconocer a sus vástagos, pero aceptan en la práctica la inequidad. En contraste, los personajes femeninos son presentados como admirables -madre e hijas- en su calidad de trabajadoras que ejercen un oficio digno, tras la muerte del padre proveedor. Esta revalorización del mundo popular, que lo convierte en protagonista de las piezas, es una de las condiciones -y novedades- del género melodramático. En él, el bajo pueblo puede por primera vez, "ver en escena sus desventuras y miserias; situaciones que antes les estaban prohibidas frente a la preponderancia del drama burgués" (Larraín y Figueroa 26). Consecuentemente, los diálogos de las afectadas por la afrenta a la honra evidencian la polaridad de perspectivas existente entre las clases, otra característica del género, lo que las lleva a cuestionar la

\footnotetext{
${ }^{15}$ Julio Walton Hesse (c. 1894- c. 1945) "era una figura [...] importante del grupo Rosa Náutica aunque su nombre no aparece en las antologías ni en las historias literarias. Como pasó con la mayoría de los jóvenes que firmaron el manifiesto, Walton participó en el movimiento más como promotor que como creador [...] El aullido de las rameras parece ser el único texto mayor de J. Walton $\mathrm{H}$. El manuscrito, después de unas peripecias verdaderamente surrealistas, recabó en los fondos de la Biblioteca Nacional de Hungría, en Budapest" (Scholz 75-76). La obra teatral aquí analizada ganó el segundo lugar del concurso de la Federación de Estudiantes de Valparaíso en 1919 y fue publicada en el mismo año por Ediciones Siembra.
} 
utilidad de las leyes, evidenciando que sufren una doble discriminación, la de ser pobres, además de mujeres

LEONOR: No necesitamos de vuestras leyes. [...] ¿Cuándo han amparado a los pobres? El dinero y nada más que el dinero es el que compra fallos justos [...]

MARGARITA: Las leyes las hicieron los hombres para los hombres. Nosotras, en vuestro concepto, somos poco más que bestias de carga.

CARMEN: Ustedes con sus leyes están prohibiendo y obstruyendo la felicidad de un ser que todavía no nace. Con esos hombres tendrán que verse más tarde. Han de comprender lo terrible que tiene que ser la venganza de esos huachos a los que ahora todo les niegan (Walton $\mathrm{s} / \mathrm{p}$ ).

El conflicto planteado se resuelve, al igual que en la obra precedente, mediante una acción individual dentro del universo poético. A través del personaje de Antonio, el pintor, se propone la idea del artista como ser consciente y sensible, posicionado en un lugar superior en términos morales al del resto de su clase. Siguiendo esa línea, la pieza termina con un encendido y emotivo llamado a ejercer la responsabilidad parental y a hacerse cargo de los vástagos, en virtud de lo que manda el corazón, como encarnación de una ley de la conciencia.
ANTONIO: La cobardía nos hace verdugos de nuestros propios hijos. Debemos negarlos porque en los códigos existe un párrafo que nos autoriza a ser canallas; porque nos avisa que entre los hombres hay una categoría especial que se titula: hijos naturales. [...] Sí, conscientemente lo hago porque mi corazón me lo dicta. Iré contra todos los prejuicios, sin miedo a nadie. [...] Tu hijo no será el hijo de nadie, será el hijo mío. (Walton s/p)

Formalmente, esta obra presenta rasgos particulares. Si bien los parlamentos de los personajes son melodramáticos -como ya se ha comentado- y recurren a situaciones emocionales extremas para influir en la recepción del público, las didascalias aparecen como una mirada distanciada de la acción, proponiendo una reflexión irónica sobre el teatro como elaboración ficcional. La lectura de las acotaciones expone al lector a un lenguaje diferente al de los diálogos, que obliga a alejarse del relato de los hechos y la 
Artículo. Verónica Sentis Herrmann y Braulio Rojas Castro. "Huachos, rotos y putas. La dramaturgia de Valparaíso frente a la cuestión social".

historia de los personajes, para tomar conciencia de su factura. Un ejemplo, entre varios, es el comienzo del segundo acto, en el que se lee:

La escena estará dividida en dos por un tabique perpendicular [...] LA PRIMERA: A la derecha la pieza de los estudiantes de leyes en casa de misiá Panchita, honorable matrona que por un bendito milagro de la Providencia, no saldrá a escena; a pesar que de mil amores lo haría [...] En esta pieza todo es por pares para evitar discusiones [...] LA SEGUNDA: Una cama, una silla, un velador [...] (;Aguarda con "El pintor Pereza de Pezoa Véliz”!) [...] (nota: aquí no hay pares. Es la pieza de los nones) (Walton s/p)

De este modo, el texto hace uso de un recurso metateatral, que le permite al autor opinar burlonamente sobre elementos de la escena, tales como la supuesta intención de misiá Panchita, personaje que no aparece nunca dentro de la obra. Alude también a un poema de Pezoa Véliz, como un intertexto irónico que desacraliza el mundo de los pintores bohemios del puerto, e incorpora comentarios lúdicos y absurdos, como "la pieza de los nones". A través de este procedimiento, Walton propone un tono farsesco que se adelanta a En la Luna, de Huidobro, pero sólo a nivel de las acotaciones, pues los parlamentos de los personajes, como ya decíamos, se ajustan totalmente al melodrama social en boga.

Lo anterior es indicador de la evolución artística de este creador en particular, si consideramos que Walton fue fundador y participó entre 1920 y 1921 en Rosa Náutica, grupo vanguardista de Valparaíso. En ese contexto publicó poemas como El aullido de las rameras (Scholz), que si bien mantiene una continuidad temática al plantearse como "un debate sobre la situación social de las clases marginadas y explotadas [...] termina por decantarse hacia el lenguaje del grito, de la exclamación" (Nordenflycht La vanguardia 126), presentando innovaciones formales de carácter expresionista. Habría, entonces, que entender esta pieza como una producción bisagra entre dos períodos del autor. Un primer momento en el que asume aún los cánones teatrales de la época, marcado por el melodrama social, y una segunda etapa en gestación, que resaltará por su novedad estilística, pero ya exclusivamente en el mundo de la lírica. 
Otro ejemplo de obra porteña sobre "la cuestión social" es Rajadiablos" ${ }^{16}$, de Carlos Barella Martínez. La pieza presenta en el rol protagónico a Domingo Astudillo, alias Rajadiablo, trabajador esforzado y ladrón rehabilitado. Su vida ha sido una sucesión de dificultades, siendo la primera de ellas su nacimiento, hijo huacho que a la muerte de su madre quedó en total desprotección. Para sobrevivir trabajó desde niño en condiciones de explotación y bajo la sospecha de la policía, quien lo ha perseguido toda su vida por el solo delito de ser pobre.

RAJADIABLO: [...] estoy aburrío... qué tanto será. Hace diez años que ando mesmamente como una bola guacha, de un lao pal otro [...] Claro, como era guacho... naiden respondía por mí. [...] Ya ve, ahora la policía me anda buscando.

ROSITA: ¿Y tu papá...?

RAJADIABLO: Mi paire debe haber sío un gran sinvergüenza. Nunca hei sabio de él. [...] Siempre solo, yo conozco el hambre, yo ei dormío meses enteros botao en los cauces. Ei trabajao de too: lustriaor, mercuriero... gásfiter, carretonero... de too. (Barella, citado en Sentis, La ciudad 13-14)

A pesar de las penurias, Rajadiablos concibe el trabajo esforzado como el único camino para superar su condición. No quiere cambiar su estatus social ni la estructura de clases, como sí lo hacía el imaginario teatral anarquista y filocomunista de la época, sino que corresponde a una idealización del mundo popular. Vale decir a un "discurso moralizante que apuntaba a la construcción de antinomias. Por un lado, la pobreza digna (representada en sujetos populares con fuerte apego a las tradiciones religiosas y sociales, y plenamente comprometidos con las formas imperantes de relaciones laborales) y por otro la pobreza decadente (que hablaba de individuos carentes de disciplina laboral, volcados a la satisfacción personal de sus deseos y carentes de religión)" (Muñoz 187). En consecuencia con dicho discurso, el texto propone que el bajo pueblo debe enorgullecerse de su rol de obrero y trabajador, engranaje indispensable para el desarrollo de la patria.

\footnotetext{
${ }^{16}$ Si bien esta pieza fue estrenada en Santiago en 1928 por la reconocida compañía de Evaristo Lillo, su primera edición como texto dramático es del año 2019, dentro de la antología web La ciudad como dramaturgia exhumada, www.historiadelteatroenvalparaiso.cl
} 
Artículo. Verónica Sentis Herrmann y Braulio Rojas Castro. "Huachos, rotos y putas. La dramaturgia de Valparaíso frente a la cuestión social".

RAJADIABLO: No es cierto. Tú ya no erai roto... tenís traza de caballero. $[\ldots]$

TRIPULINA: ¡Pero a quien no le gusta ser más! [...]

RAJADIABLO: Mentira, ¿cual'e yo? [...]. Te habís botao a caballero y estai en el aire, porque no erei ni roto ni caballero [...] A nadie le gusta ser roto.[...] A toos les ha dao ahora por hacerse volche... volche... ¿cómo se ice?

TRIPULINA: Volcheviquiti... comunista, federao, cosas de las Uropas.

RAJADIABLO: [...] El roto con poncho de cuatro puntas ya no existe en este rincón del puerto. [...]. No quiero tener más de lo que tengo, ni quiero ir a los clús, ni comprarme de esos sombreros pirifláuticos porque estoy convencío qu'el que nació pa' ojotas, contra ná compra zapatos. (Barella, citado en Sentis, La ciudad 65-66)

La obra recupera así la idea de "el roto" como encarnación del acervo identitario y del valor moral de la nación, exaltando a los trabajadores que con su esfuerzo consciente y responsable contribuirán al desarrollo del Chile moderno. No estamos, en este caso, frente a una dramaturgia movilizadora que promueva cambios estructurales, sino a una pieza que busca validar y enaltecer dentro del mundo poético a los pobres, sin que estos abandonen su condición de tales, en consonancia con lo declarado en la encíclica De rerum novarum. El desenlace viene a reforzar este discurso a través de un guiño naturalista, mostrando la muerte de Rajadiablos en un duelo a cuchillos, como la confirmación de la imposibilidad de cambiar el destino que el lugar de nacimiento ha trazado. La explicación hay que buscarla en el origen de clase del autor, hombre de letras y arquitecto, perteneciente a lo que Villegas define como un sector medio e ilustrado, que denuncia las inequidades del mundo marginal y propone un modo de enfrentarlas, sin pertenecer a él (Villegas 147).

En cuanto al estilo, la pieza corresponde nuevamente a un melodrama social ${ }^{17}$, esta vez con giros cómicos, que muestra la destreza del dramaturgo respecto al recurso teatral, en virtud del principio de unidad en la variedad. Es una obra de bajos fondos porteños, con personajes protagónicos populares que generan identificación en el público asistente. Plantea un conflicto polarizado entre buenos -los pobres- y malos -los pequeños

\footnotetext{
${ }^{17}$ Si bien el autor la define como "comedia en tres actos", hay que entender dicha clasificación en términos genéricos en los que la voz comedia corresponde a cualquier tipo de texto dramático, a la usanza del teatro del siglo de oro español.
} 
burgueses-, recurriendo a registros emocionales exacerbados que buscan la catarsis de los espectadores.

Dentro de esta misma línea se encuentra otra pieza posterior del propio autor, La calle del dolor y del pecado (1935) ${ }^{18}$, que insiste en el mundo marginal ya descrito. A través de una arista diferente, que exhibe un paisaje distinto de la vida del puerto, vemos a Marucha, prostituta joven y cándida que ha caído en la desgracia como resultado del abandono de un hombre. Cuando parece que la mujer va a recuperar su honra a través de un amor puro que desea rescatarla del ambiente, la insensibilidad y los prejuicios de la alta burguesía porteña se lo impiden. A pesar de ello, el conflicto tampoco es planteado como una tensión de clases que deba resolverse a través de otra estructura social, sino como el resultado de los prejuicios particulares del padre de su joven enamorado, quien para mantener las apariencias recurre al engaño de su propio hijo, condenándola nuevamente a la desgracia.

MARUCHA: Era demasiada felicidad para mí [...] ¿Por qué me lo ha quitado?, ¿ah?... ¡es que les hacia algún daño?... la maldad... la maldad...

CABALLERO: Señorita, si se pone Ud. intransigente...

MARUCHA: Tiene Ud. razón... todavía para serle grata a Ud. tengo que parecerle perfectamente educada [...] ya todo ha terminado... todo... ha hecho Ud. lo que merecía una mujer de la calle. [...] me dejan sola, mortalmente sola en esta calle por donde cuando pasa el amor deja a las mujeres llorando como a mí, como a todas [...] (Barella, citado en Sentis, Valparaíso 129)

Así planteada, la prostitución es entendida como el resultado de la maldad de un individuo específico, no como la encarnación de un capitalismo feroz en el que para vivir, cuando nada se posee, hay que vender el cuerpo en el mercado. ${ }^{19}$

El registro formal es, al igual que en la producción anterior, melodramático. El conflicto no ocurre en el fuero interno de los personajes, sino en la tensión de clases entre el mundo

\footnotetext{
${ }^{18}$ A pesar de que esta pieza fue estrenada en Santiago en 1935 por la compañía de Emperatriz Carvajal, su primera edición como texto dramático es del año 2019, dentro de la Antología Valparaíso en Escena, de RIL Editores.

${ }^{19}$ Se le puede contraponer con la forma como tematiza la prostitución Carlos del Mudo, en Ciudad podrida (1937) internalizando la causa en el sujeto femenino: "buscando un algo de sinceridad -imposible de hallarla entre la gente honrada y honorable- vine a cobijarme entre las prostitutas como una última esperanza... No pongo las manos al fuego por ellas. Las hay malas, pero la mayoría son peores. Qué virtud podrá pedirse a un ser que vende su cuerpo como quien bebe un vaso de agua" (12).
} 
Artículo. Verónica Sentis Herrmann y Braulio Rojas Castro. "Huachos, rotos y putas. La dramaturgia de Valparaíso frente a la cuestión social".

popular y la burguesía. Marucha es la encarnación de la bondad, moralmente superior, a pesar de ser una puta. El padre de su joven enamorado es artero e inconmovible al verdadero amor, a pesar de su educación y privilegios. Las emociones son exacerbadas y juegan un rol central en el desarrollo de la acción, como se observa ya en las didascalias que abren la pieza. En ellas, el autor se permite incorporar sensibles comentarios personales, subrayando desde ya la exaltación desde la cual debe interpretarse el texto

En el año 1908. Las calles del barrio de "El Puerto"
descienden tortuosas y retorcidas, abriéndose paso entre las
hendiduras de los cerros. Eran calles endiabladas.
Debatiéndose, llenas de podredumbre y miseria [...]. Baches,
vericuetos y encrucijadas, daba al pobre barrio de las rameras
un aspecto pintoresco y trágico. [...] Me olvido que esta es una
simple acotación para sentir una pena infinita por esas mujeres
que, por "diez chauchas" entregan a cualquiera su ternura sin
ternura. Su amor sin amor. Por esas mujeres que se desnudan
con indiferencia mortal, para entregar su sexo ultrajado a la
bestialidad de un sensualismo sin ilusión (Barella, ctd en Sentis,
Valparaíso 81-82).

\section{A modo de conclusión}

Tanto la producción literaria como la producción teatral porteña del primer tercio del siglo $\mathrm{XX}$, se hicieron cargo temáticamente de la cuestión social que instaló la encíclica papal De rerum novarum en 1891, en consonancia con las producciones santiaguinas del mismo período. A través de sus registros particulares, las creaciones teatrales y literarias de la época denunciaron la marginalidad a la que habían sido relegados "el roto", "el huacho" y "la prostituta" en la ciudad-puerto, como el costo asumido por las clases bajas dentro del nuevo orden modernizador. Las piezas presentaban como novedad un universo poético en el que los protagonistas eran personajes populares considerados positivamente, en la medida en que abandonaban sus vicios de clase (alcoholismo, vagancia, lubricidad, etc.). Vale decir, cuando se sumaban como engranaje útil dentro del modelo económico capitalista.

Salvo contadas excepciones, fue una producción artística funcional a las oligarquías y a la construcción unitaria de la nación, la que intentó validar el disciplinamiento emprendido por el Estado desde la fundación de la república. 
Lo anterior se explica en el origen social de los autores, tanto literatos como dramaturgos, la mayoría de ellos miembros de una clase media en ascenso y con estudios universitarios o inscritos en un proceso de ilustración. Desde su distante experiencia pretendían otorgarle voz a los sin voz, esbozando piezas sobre los bajos fondos porteños a través de una cercanía ilusoria con el mundo recreado. Sus producciones correspondían a discursos de los sectores medios en representación de los sectores emergentes, que denunciaban la existencia de sectores marginados del bienestar económico, sus condiciones vitales, el espacio de la pobreza y su exclusión de los beneficios de la modernización (Villegas, 2005). A pesar de ello, hay que entender el aporte de estos creadores no sólo como un simple reflejo o documentación de su contexto de producción, sino como "actores en el proceso de pensar un país, como expresión y constructores de imaginarios, y como sensores de conflictos [...] de un país en proceso de irse constituyendo" (Hurtado, Dramaturgia 20), en el que las clases populares comenzaban a tener cabida -y validezdentro del imaginario social.

Por otra parte, si observamos los recursos formales a través de los cuales se plasmaron las temáticas arriba señaladas, se advierten aquí diferencias entre el teatro y la literatura local. El primero, fue durante el período un arte colectivo independiente, que no contó con ningún tipo de presupuesto o apoyo estatal. La escena chilena, y más aún la de tema porteño de la época, se vio en la necesidad de producir piezas que convocaran al incipiente público. En ese contexto, y debido a que vivían exclusivamente del valor de las entradas, el melodrama aparecía como un género de amplia convocatoria. Proponía el mundo popular como protagonista. Delineaba personajes tipos que producían una rápida identificación, en su adscripción sin ambages al bien o al mal. Y, por último, apelaba a recursos emocionales generadores de una experiencia catártica, que aliviaba las frustraciones de la propia vida de los asistentes. Un teatro vanguardista o de investigación formal habría significado, en la práctica, la desaparición de las compañías, quienes no habrían podido mantenerse en el tiempo por razones económicas.

Un segundo aspecto, que podría explicar la reticencia del teatro para adoptar modelos vanguardistas dentro de la producción de la época, - y que sería necesario profundizar en un estudio más específico-, es la diferencia de códigos. Si bien la literatura y los textos dramáticos responden a lo que se entiende como código escrito, el segundo es un texto 
Artículo. Verónica Sentis Herrmann y Braulio Rojas Castro. "Huachos, rotos y putas. La dramaturgia de Valparaíso frente a la cuestión social".

que está concebido, desde el comienzo, para ser dicho de tal modo que parezca espontáneo, vale decir, como si no hubiese sido escrito. De hecho, durante la representación sólo existe en su oralidad y adquiere algunas características de este código, que dicen relación con su conservadurismo: el espectador lo va a oír una sola vez, por lo que debe seguir un orden. La información se transfiere no sólo a través de la lengua, sino que utiliza también un conjunto de códigos no verbales. Se percibe sintagmáticamente, se puede corregir, pero no borrar ni eliminar procesos experimentales que su autor considere fallidos $\mathrm{y}$, por último, se modifica en la interacción convivial con el otro. En contraposición, la literatura, como código exclusivamente escrito, posee un alto grado de elaboración que le permite al autor un detallado trabajo con la forma. Puede corregir, borrar las huellas de su experimentación con el texto hasta proponer una forma cerrada, que no se modifica en su relación con el lector. Por lo mismo, la literatura, cuando es de vanguardia puede, como plantea Ong “descomponer o disimular las tramas de sus narraciones [pero] lleva la huella de la escritura y la tipografía. [...] No puede sustraerse a hacerlo de una forma elaborada y académica" (130). Lo anterior nos permitiría entender, por ejemplo, el doble registro que propone El hijo de nadie, de Walton, que plantea un discurso lineal, antinómico y de carácter melodramático en los parlamentos de los personajes, -vale decir en los textos que van a ser escuchados por el espectador-, pero incorpora comentarios absurdos en las didascalias, aspecto de una obra dramática que sólo puede conocerse a través de su lectura y no por su representación.

Dentro de este presupuesto, el teatro chileno sólo habría podido absorber elementos de la vanguardia posteriormente, cuando ya estaba consolidado como un género estable dentro de la producción artística nacional. Vale decir, cuando se contaba con un público formado y conocedor de los modos tradicionales de narración escénica, experticia que lo volvía capaz de apreciar las experimentaciones formales propuestas por los creadores.

Esta etapa de desarrollo no se logró sino hasta fines de los años '50, veinte años después de la profesionalización emprendida por los teatros universitarios, momento que coincide con el tardío estreno de En la Luna, de Huidobro, y que precede a la aparición del teatro del absurdo a nivel local, en los años sesenta. 
Nueva Revista del Pacífico 2020, № 72, (pp. 301-324). ISSN (e) 0719-5176

\section{Referencias bibliográficas}

Acereda, Alberto. El antimodernismo. Debates transatlánticos en el fin de siglo. Palencia: Ediciones Cálamo, 2011.

Alberdi, Begoña. "Valparaíso a través de sus revistas: Un modelo de vanguardia heterogénea." Acta Literaria 47 (2013): 35-50. https://dx.doi.org/10.4067/S0717$\underline{68482013000200003}$

Anónimo. Captura y fusilamiento de Dubois, Publicado en Sentis, Verónica; Saavedra, Lorena \& Ferretto, Giulio. La ciudad como dramaturgia exhumada. Antología teatral porteña 1869-2019. Recuperado de www.historiadelteatroenvalparaiso.cl, 2019.

Balat, Carmen. "Temas de la narrativa moderna chilena: del romanticismo al naturalismo." Revista Contextos 23 (2010): 137-153.

Barella Martínez, Carlos. La calle del dolor y del pecado, publicado en Sentis, Verónica. Valparaíso en escena. Antología de dramaturgia porteña 1870-2015. Santiago de Chile: RIL, 2019

--.Rajadiablos. Sentis, Verónica et al. La ciudad como dramaturgia exhumada. Antología teatral porteña 1869-2019. Recuperado www.historiadelteatroenvalparaiso.cl, 2019.

Bentley, Eric. La vida del drama. Buenos Aires: Paidós, 1964.

Bosshard, Marco Thomas. La reterritorialización de lo humano. Una teoría de las vanguardias americanas. Pittsburgh: IILI, 2010.

Cánovas, Rodrigo. Sexualidad y cultura en la novela hispanoamericana. La alegoría del prostíbulo. Santiago de Chile: LOM, 2003.

Cárdenas, Vania. El orden gañan. Historia Social de la Policía. Valparaíso 1896-1920. Concepción: Editorial Escaparate, 2013.

Chile. Ley de filiación 19.585, de 13 de octubre de 1998 [en materia de filiación]. Web http://bcn.cl/1ux3t

Chandía, Marco. La cuadra. Pasión, vino y se fue... Cultura popular, habitar y memoria histórica en el Barrio Puerto de Valparaíso. Santiago de Chile: RIL, 2013.

Conejeros, Juan Pablo. La influencia cultural francesa en la educación chilena 18401880. Santiago de Chile: Universidad Católica Silva Henríquez, 1999.

Correa-Díaz, Luis. "América y Cervantes/El Quijote: el caso de Chile.” Revista Chilena de Literatura 72 (2008): 127-147.

Del Mudo, Carlos. La ciudad podrida. Valparaíso: Imprenta Aurora de Chile, 1937.

Durán-Cerda, Julio. Esquema de evolución del cuento en Chile. El cuento hispanoamericano ante la crítica. (Dir.) Enrique Pupo-Walker. Madrid: Editorial Castalia, 1973. 296-321.

Edwards Bello, Joaquín. El roto. Santiago de Chile: Editorial Universitaria, 2009.

Figueroa, Soledad; Larraín, Javiera. Espérame en el cielo, corazón. El melodrama en la escena chilena de los siglos XX y XXI. Chile: Cuarto Propio, 2017.

Hernández P. Roberto y Jule Salazar G. De la policía secreta a la policía científica. Proceso histórico de Policía de Investigaciones de Chile. 1864-1927. Santiago de Chile: Policía de Investigaciones de Chile, 1994.

Hozven, Roberto. "El Quijote, Cervantes y los ensayistas chilenos." Estudios Públicos 100 (2005): 325-336.

Hurtado, María de la Luz. Dramaturgia chilena 1890-1990. Autorías, textualidades, historicidad. Santiago de Chile: Frontera Sur, 2011. 
Artículo. Verónica Sentis Herrmann y Braulio Rojas Castro. "Huachos, rotos y putas. La dramaturgia de Valparaíso frente a la cuestión social".

—. Teatro chileno y modernidad: identidad y crisis social. Irvine, California: Gestos, 1997.

Illanes, María Angélica. "AUSENTE, SEÑORITA" El niño chileno. La escuela para pobres y el auxilio 1890/1990. Santiago de Chile: JUNAEB, 1991. Digital.

Kowzan, Tadeusz. El signo y el teatro. España: Arco Libros- La Muralla, 1992.

León XIII. De rerum novarum. http://www.vatican.va/content/leoxiii/es/encyclicals/documents/hf_l-iii_enc_15051891_rerum-novarum.html

Lepe- Carrión, Patricio. El contrato colonial de Chile. Ciencia, racismo y nación. Quito: Abya Yala, 2016.

Méndez Carrasco, Armando. El mundo herido. Santiago de Chile: Editorial Cultura, 1955.

Montecinos, Sonia. Madres y huachos. Alegorías del mestizaje chileno. Chile: Cuarto Propio-CEDEM, 1991.

Montero Yavar, Gonzalo. "Periferia, cosmopolitismo y modernidad simbólica. La poesía de Neftalí Agrella en las revistas de la vanguardia chilena." Mapocho. Revista de Humanidades (2010): 37-48. http://www.memoriachilena.gob.cl/archivos2/pdfs/MC0048556.pdf .

Muñoz González, Luis y Dieter Oelker Link. Diccionario de Movimientos y Grupos Literarios Chilenos. Concepción: Ediciones Universidad de Concepción, 1993.

Muñoz, Jorge. "Narrar el cotidiano de los portadores de la revolución social: proyecto político y artístico del proyecto vanguardista Rosa Náutica, Valparaíso, Chile, (1922-1923)." Revista Izquierdas $29 \quad$ (2016): $186-204$. https://dx.doi.org/10.4067/S0718-50492016000400007

Nordenflycht, Adolfo de. «La vanguardia de Valparaíso: expresionismo de/en la $\begin{array}{lllll}\text { periferia.» } & \text { Estudios } & \text { Filológicos } & 47 & \text { (2011): }\end{array}$ http://dx.doi.org/10.4067/S0071-17132011000100007

-. «Quiñónez: poeta, olvidado y porteño (literaturas regionales e imaginarios geoculturales en Chile.» Estudios Filológicos 38 (2003): 49-59. https://dx.doi.org/10.4067/S0071-17132003003800004

Ong, Walter. Oralidad y escritura. Tecnologías de la palabra. México: Fondo de Cultura Económica, 1987.

Pezoa Véliz, Carlos. Tierra Bravía. Santiago de Chile: Gaceta Ediciones, 2018.

Piña, Juan Andrés. Historia del teatro en Chile 1890-1940. Santiago de Chile: RIL, 2009.

Rojas Castro, Braulio. "Remenyik y Agrella, los años salvajes de las vanguardias en Valparaíso y la dimensión transoceánica de la modernidad. Creación poética, conflicto político y cohesión social." Narrativas de la cohesión social en publicaciones periódicas del Cono Sur americano (1900-1940). Ed. Ricardo González Leandri y Armando V. Minguzzi. Madrid: Polifemo, 2019. 331-353.

-. "La constelación del punto de fuga. El imaginario porteño y la minoridad." Discursos/prácticas $3 \quad$ (2010): 42-64. http://www.discursospracticas.ucv.cl/html/articulo_rojas.html

Salazar, Gabriel. Movimientos sociales en Chile. Santiago de Chile: Uqbar, 2012.

-. Ser niño "huacho" en la historia de Chile. (siglo XIX). Santiago de Chile: LOM, 2006.

Salazar, Gabriel y Julio Pinto. Historia Contemporánea de Chile I. Estado, legitimidad y ciudadanía. Santiago de Chile: LOM, 1999. 
Scholz, László. "El aullido de las rameras (Un texto inédito del grupo 'Rosa Naútica')." Hispamerica 20.60 (1991): 73-84. https://www.jstor.org/stable/20539598

Sentis Herrmann, Verónica. Valparaíso en escena. Antología de dramaturgia porteña 1870-2015. Santiago de Chile: RIL, 2019.

- Historia del teatro en Valparaíso 1950-2000. Recuperado de www.historiadelteatroenvalparaiso.cl, 2012.

Sullivan, Maurice. "La influencia de Cervantes y de su obra en Chile." Anales Cervantinos (1952): 288-310. https://search.proquest.com/openview/42aaf2966a6fbc6bb3bb3076ff712e15/1?pqorigsite $=$ gscholar $\& \mathrm{cbl}=1818275$

Versényi, Adam. El teatro en América Latina. Gran Bretaña. Cambridge: University Press, 1996.

Villegas, Juan. Historia multicultural del teatro y las teatralidades en América Latina. Irvine. California: Gestos, 2005.

Walton, Julio. El hijo de nadie. Valparaíso: Siembra, 1919. 